Am J Psychiatry Vol. 132(8):868-870 (1975)

ISSN: (print 0002-953X)(online 1535-7228)

This is a peer reviewed pre-print version of the following article: Caffeine Versus Methylphenidate and $d$-Amphetamine in Minimal Brain Dysfunction: A Double-Blind Comparison, which has been published in final form at: http://www.appi.org http://www.appi.org/SearchCenter/Pages/Journal.aspx?ItemId=AJP http://ajp.psychiatryonline.org/article.aspx?articleid=154332

(C) 1975 American Psychiatric Publishing, Inc.

\title{
Caffeine Versus Methylphenidate and $d$-Amphetamine in Minimal Brain Dysfunction: A Double-Blind Comparison
}

\author{
By LCDR Robert D. Huestis, MC, USN, L. Eugene Arnold, M.ED., M.D., and \\ Donald J. Smeltzer, M.A.
}

The authors compared the efficacy of caffeine, methylphenidate, and d-amphetamine in children with minimal brain dysfunction using a double-blind crossover design. The slight improvement with caffeine was not significantly better than placebo. Both prescription drugs resulted in significant improvement and were significantly superior to caffeine. The authors suggest that the discrepancy between these results and an earlier, more optimistic report may stem from the use in this study of pure caffeine rather than whole coffee.

In recent years a growing public and professional concern about the use of Schedule II stimulants to treat hyperkinetic children has sparked a desire to find a "safer" medication that has equal efficacy. Caffeine has been one of the drugs proposed as an alternative. Schnackenberg's initial report of a pilot study was promising (1); however, he cautioned that controlled studies were necessary. We thought it would be particularly useful to compare caffeine with the two most widely accepted and prescribed agents, $d$-amphetamine and methylphenidate. Although our study is not complete, the results seem so clinically relevant that we are reporting a preliminary analysis of the first half of the sample.

\section{Method and Design}

After an initial two-week placebo washout, caffeine, $d$-amphetamine, and methylphenidate were compared in a double-blind randomized Latin square crossover design. The subjects were 18 children consecutively admitted to the Ohio State University Child Psychiatry Clinic (12 boys and 6 girls, mean age $=8.5$ years) who met the following criteria:

1. Diagnosable minimal brain dysfunction with such symptoms as hyperactivity, distractibility, short attention span, incorrigibility, labile explosiveness, uncoordination, and perceptuomotor problems.

2. A total score of 24 or more on the first six items of Davids' Hyperkinetic Rating Scale (2).

3. Age between 5 and 12 years.

4. Enrollment in some sort of school setting in order to obtain teachers' ratings.

5. No psychoactive medications in the preceding month.

6. Failure to respond to a two-week placebo washout period.

In the initial two-week period, 10 children received "true" placebo and 8 received a combination of vitamins. Because comparison of these two groups revealed no significant differences between the true placebo and the vitamin group, results for these patients were pooled and reported as placebo scores for the whole sample. Only 2 subjects, both of whom had received the true placebo, were placebo responders.

All medications were dispensed by a pharmacist who randomized the order of drug 
assignment. The matched dosage forms were white opaque capsules in the following strengths: 80 $\mathrm{mg}$ of caffeine, $5 \mathrm{mg}$ of $d$-amphetamine, and $10 \mathrm{mg}$ of methylphenidate. These dosage ratios were selected to reflect approximate relative potencies suggested by the literature. Dosage size was selected so that one to six capsules would include the recommended daily dosage. Specifically, Schnackenberg (1) recommended 200 to $300 \mathrm{mg}$ of caffeine per day and stated that increasing the dosage above $300 \mathrm{mg}$ did not elicit any further improvement.

Each of the drug conditions lasted three weeks, with a minimum of three telephone consultations for adjustment of dosage (the average number of contacts was six). The ascending dosage schedule for each medication was as follows: day 1 -one capsule in the morning, day 2 - one in the morning and one at noon, and day 3-two in the morning and one at noon. All parents were instructed to contact the clinic on the fourth day, at which time further adjustments were made depending on information they provided.

At each of the visits, including the predrug assessment, the following information was collected: 1) a parents' symptom checklist reported by Arnold and Smeltzer (3), 2) Conners' Teachers' Behavior Checklist (4), 3) Davids' Hyperkinetic Rating Scale completed by the parents (2), 4) Davids' Hyperkinetic Rating Scale completed by the teacher, and 5) a target symptom assessment in the manner described by Arnold and associates (5).

\section{Results}

Since the amount of medication for each subject was individualized during the three-week interval, it is important to note that all the subjects received at least $300 \mathrm{mg}$ of caffeine per day for at least one week. The optimal effective dosage range for $d$-amphetamine was 5 to $25 \mathrm{mg}$ (average $=20 \mathrm{mg}$ ) and for methylphenidate, 30 to $60 \mathrm{mg}$ (average $=40 \mathrm{mg}$ ).

Table 1 shows the mean target symptom ratings by two psychiatrists for each of the five visits, the average rating for Davids' Hyperkinetic Rating Scale, as reported by both parents and teachers, the average ratings from the symptom checklist by parents, and the average ratings of the behavior checklist by teachers.

Paired $t$ tests of all these data clearly indicate that caffeine was not significantly more effective than placebo, but both $d$-amphetamine and methylphenidate were $(\mathrm{p}<.01)$. More importantly, comparison of caffeine to methylphenidate and $d$-amphetamine shows caffeine to be significantly less effective. The one exception to this pattern was the nonsignificance of the methylphenidate versus caffeine comparison on the teachers' hyperkinetic rating scale. In all other instances, both $d$-amphetamine and methylphenidate were significantly superior to both caffeine and placebo. The two effective drugs were not significantly different from each other, nor was placebo different from the predrug condition.

Upon completion of the study, 16 subjects were found to have improved sufficiently to warrant continuation of one of the three medications. Nine took $d$-amphetamine, 6 took methylphenidate, and 1 took caffeine. (One month after completion of the study, the child on caffeine had to be switched to $d$-amphetamine because his previous symptoms returned.)

\section{Discussion}

Preliminary results of this study seem to indicate that caffeine does not offer hyperkinetic children the same therapeutic benefits as $d$-amphetamine and methylphenidate. It should be added that the clear differences illustrated in table 1 were entirely consistent with the clinical judgment of the experimentally blind clinician-investigator. Difficulties repeatedly arose during the study after a child who had received either $d$-amphetamine or methylphenidate was switched to caffeine. 
Usually, this involved a parents' request to terminate that three-week trial. The caffeine treatment also prompted four spontaneous notes from teachers inquiring as to what had caused such rapid deterioration following obvious gains in previous trial weeks.

Perhaps a word should be said about the rather high percentage of children who were found to be drug responders (89 percent). This is probably a reflection of the fact that the study included two medications known to be helpful in this disorder. This finding would seem to emphasize the clinical value of trying more than one stimulant, not only when the child fails to respond to the first medication tried but also when there is benefit, but not to the degree expected, or there are annoying side effects. Both efficacy and side effects were considered in the decision as to which medication (if any) a child would receive at the completion of the study. Since the subjects had tried both $d$-amphetamine and methylphenidate, we were able to feel confident that the medication had been "matched" to the individual child.

The small sample size does not warrant comment regarding the nonsignificant difference between $d$-amphetamine and methylphenidate. This issue may be clarified by our present efforts to expand the sample to its originally projected size.

Another reason for sample expansion is that the nonsignificant trend for caffeine to be slightly more effective than placebo in this analysis may reach significance in a larger sample. Caffeine may have a real efficacy that was not apparent in this study because of small sample size. This could carry practical clinical implications in the risk-benefit decision. Of course, caffeine's significant inferiority to the two prescription stimulants is not likely to disappear with sample expansion. However, if caffeine is considered much safer and does prove to have some slight efficacy, it might make sense in many cases to try it before proceeding to "dangerous" drugs.

\begin{tabular}{|c|c|c|c|c|c|}
\hline & Predrug & & & & \\
\hline Measure & & Placebo & Methylphenidate & $d$-Amphetamine & $\begin{array}{l}\text { Caffein } \\
\text { e }\end{array}$ \\
\hline $\begin{array}{l}\text { Target symptom rating, psychiatrists } \\
\text { (l=best, 9=worst)* }\end{array}$ & 5.00 & 5.33 & 3.42 & 3.22 & 4.97 \\
\hline $\begin{array}{l}\text { Hyperkinetic Rating Scale, parents } \\
(1=\text { least and } 6=\text { most } \\
\text { hyperkinetic })^{* *}\end{array}$ & 5.14 & 4.97 & 4.21 & 4.13 & 4.89 \\
\hline $\begin{array}{l}\text { Hyperkinetic Rating Scale, } \\
\text { teachers*** } \\
\text { Symptom checklist, parents ( } 1=\text { no }\end{array}$ & 4.92 & 4.90 & 4.11 & 3.88 & 4.67 \\
\hline Behavior checklist, teachers (1 =no & $\begin{array}{l}2.37 \\
2.34\end{array}$ & $\begin{array}{l}2.31 \\
2.36\end{array}$ & $\begin{array}{l}1.86 \\
1.91\end{array}$ & $\begin{array}{l}1.82 \\
1.86\end{array}$ & $\begin{array}{l}2.14 \\
2.32\end{array}$ \\
\hline
\end{tabular}

*Significant differences (paired t tests for all comparisons): placebo versus both methylphenidate and $d$-amphetamine $(\mathrm{p}<.001)$ and caffeine versus both methylphenidate and $d$-amphetamine $(\mathrm{p}<.01)$.

**Significant differences $(\mathrm{p}<.01)$ : placebo versus both methylphenidate and $d$-amphetamine and caffeine versus both methylphenidate and $d$-amphetamine.

***Placebo versus both methylphenidate and $d$-amphetamine $(\mathrm{p}<.001)$ and $d$-amphetamine versus caffeine $(\mathrm{p}<.001)$.

$†$ Placebo versus both methylphenidate $(\mathrm{p}<.01)$ and $d$-amphetamine $(\mathrm{p}<.001)$ and caffeine versus both methylphenidate and $d$-amphetamine $(\mathrm{p}<.05)$.

†Placebo versus both methylphenidate $(\mathrm{p}<.01)$ and $d$-amphetamine $(\mathrm{p}<.001)$ and caffeine versus both methylphenidate $(\mathrm{p}<.02)$ and $d$-amphetamine $(\mathrm{p}<.001)$. 
Table 1 Comparison of the Efficacy of Methylphenidate, d-Amphetamine, and Caffeine in 18 Children with Minimal Brain Dysfunction

One possible explanation for the discrepancy between our findings and those of Schnackenberg's pilot study (1) is that he used whole coffee, while we used pure caffeine. Could it have been something in the coffee besides the caffeine that effected the improvement he observed? This question deserves study, which could easily be done using whole freeze-dried coffee in the matched capsules. If this proved effective, a further possible refinement would be to try decaffeinated coffee to see if the other coffee constituent required the presence of caffeine to be effective.

At the present time, however, it does not appear that caffeine alone will be a very effective addition to the treatment armamentarium for minimal brain dysfunction.

\section{Acknowledgements}

At the time this work was done, LCDR Huestis was Clinical Instructor, Division of Child Psychiatry, Department of Psychiatry, Ohio State University College of Medicine, 473 W. 12th St., Columbus, Ohio 43210, where Dr. Arnold is currently Associate Professor and Director and Mr. Smeltzer is Assistant Professor of Psychiatry. LCDR Huestis is now with the Department of Psychiatry, Naval Regional Medical Center, Norfolk, Va. Address reprint requests to Dr. Arnold.

This work was supported by a grant from the Ohio Department of Mental Health and Mental Retardation.

Computer time was furnished by Ohio State University Computer Center. Matched dosage forms were provided by CIBA-GEIGY Corporation, Summit, N.J.

\section{References}

1. Schnackenberg R: Caffeine as a substitute for Schedule II stimulants in hyperkinetic children. Am J Psychiatry 130:796 -798, 1973

2. Davids A: An objective instrument for assessing hyperkinesis in children. Journal of Learning Disabilities 4:499-501, 1971

3. Arnold LE, Smeltzer D: Behavior checklist factor analysis for children and adolescents. Arch Gen Psychiatry 30:799-804, 1974

4. Conners CK: A teacher rating scale for use in drug studies with children. Am J Psychiatry 126:884-888, 1969

5. Arnold LE, Wender PH, McCloskey K, et al: Levoamphetamine and dextroamphetamine: comparative efficacy in the hyperkinetic syndrome. Arch Gen Psychiatry 27:816 -822, 1972 